\title{
Occipital Meningoencephalocele case report and review of current literature
}

\author{
Ahmed Alwahab ${ }^{1 *}$ (D), Adnan Kharsa', Alaa Nugud ${ }^{2}$ and Shomous Nugud ${ }^{3}$
}

\begin{abstract}
Background: Meningoencephalocele is a rare congenital anomaly that is characterized by herniation of brain tissue through a defect in skull. Generally, it could be divided by anatomical location of defect to occipital and frontoethmoidal. The exact etiology of this condition is unknown but many theories have been postulated. The condition is usually seen at birth but can be identified prenatally.

Case presentation: A newborn was brought to the hospital after a normal non-complicated vaginal delivery done by the ambulance personnel. The newborn had a bulging mass on the posterior aspect of the head. Therefore, he was admitted and neurosurgical consultation was done for further evaluation. Currently the patient is following up in well baby clinic as well as the neurosurgery clinic for normal development and milestones acquisition.
\end{abstract}

Conclusions: This case presents the opportunity for junior healthcare professionals to learn about a group of congenital neurological disorder in the content of a rare case presentation.

Keywords: Meningoencephalocele, Congenital cranial malformation, Congenital brain Herniation

\section{Background}

Meningoencephalocele is a type of Encephalocele. It's an abnormal leakage of cerebrospinal fluid (CSF) and herniation of brain tissue and meningeal membranes through a defect in the bony skull. It's a rare congenital condition and occurs approximately in 1 per 5000 live births [1].

It is categorized into two types according to the sac's locations: occipital and frontoethmoidal. Multiple theories have been proposed to explain the exact cause of Meningoencephalocele. Many observations and associations have been found to be co-occurring with Meningoencephalocele. Despite that, there is no single theory that clearly explains the pathogenesis of this anomaly. Therefore, it's believed to be due interaction between genetic background and environmental factors.

Meningoencephalocele is diagnosed antenatally using sonography. It can achieve diagnostic accuracy in $80 \%$ of cases [2]. Other imaging modalities including: CT scan, MRI, and MRA can also be used for further detailed evaluation but their use has been limited due to the rarity of this anomaly.

\footnotetext{
* Correspondence: a7md13@gmail.com

${ }^{1}$ College of medicine, University of Sharjah, Sharjah, United Arab Emirates Full list of author information is available at the end of the article
}

Several factors influence the prognosis of patients with Meningoencephalocele. The sac size and the amount of herniated brain tissue determines the prognosis. In addition, hydrocephaly, infections, and other anomalies accompanying the condition determine the prognosis as well. The mortality rate approaches 30\% despite the applied appropriate treatments [3].

This case reports aims to shed the light on a rare neurodevelopment congenital anomaly with a review of relevant literature.

\section{Case presentation}

A 17-h old male infant was admitted to the Neonatal Intensive Care Unit (NICU) following a spontaneous progressive labor and eventual delivery in the ambulance. His Apgar score at $1 \mathrm{~min}$ was 8 , and 9 at 5 min. Weight, length and head circumference were all within normal parameters. Upon arrival to the hospital, the pediatrician on call noted a bulging occipital mass at the site of the posterior fontanel. Mother was taken to the Operating Room to remove impacted placental tissue.

At NICU, the patient was kept in a prone position and nil per oral. Examination showed an active baby moving all limbs normally with no neurological 
deficit. Neurosurgical team was consulted and they recommended Computerized Tomography (CT) scan and Magnetic Resonance Imaging (MRI). They also recommended intubation should any problem arises. A provisional diagnosis of Meningoencephalocele was made.

On the second day of admission, the patient was discharged from the NICU and kept with his mother in the female ward. Upon taking a detailed history from the mother, she was 29 years old, gravida 4 Para $3+1$. The mother didn't attend her Antenatal Care visits for throughout this pregnancy because of travelling a lot due to personal reasons. Her past obstetrical history was significant for Gestational Diabetes Mellitus and a spontaneous abortion one and half year back. Her other children are all healthy and were delivered vaginally with no similar complaint.

Upon reviewing the $\mathrm{CT}$ scan and MRI reports, the neurosurgical team didn't recommend surgery because there was no brain tissue within the herniated sac nor was there any compression over the brain parenchyma (Figs. 1 and 2).

Follow up visit at 4-month in the well-baby clinic showed normal growth parameters and developmental milestones. General examination did not reveal any significant finding. Institutional ethical approval from the local authority at the authors affiliation was obtained and consent to publish the case report was obtained from the patient's parent during the visit.

\section{Discussion and conclusion}

Meningoencephalocele is categorized according to the location of the herniated sac into two main types: occipital and frontoethmoidal meningoencephalocele. The frontoethmoidal type predominates the Southeast Asian countries including Thailand and seen more in females, while the occipital type is more common in the western world with a predilection for males [4].

The cause of meningoencephalocele is believed to be multifactorial where genetic and environmental factors play a role. Given the observation of familial predilection, genetic background may increase the risk of developing this condition. Yet, no genes have been held responsible for causing the condition. Also, due to close relationship between meningoencephalocele and neural tube defects, folate deficiency has been believed to play a role in the pathogenesis of meningoencephalocele [5].

Meningoencephalocele is associated with facial anomalies including broad nasal root, hypertelorism, cleft lip, cleft palate, polydactyly, polycystic kidneys, ambiguous genitalia (features of Meckel-Gruber syndrome) [6], microcephaly, microagnathia and hydrocephalus.

Gregor J. et all, found that MRI could reveal the exact anatomical description of the meningoencephalocele and displaced brain structures, and showed the typical features of Chiari III malformation in some cases. It also revealed the configuration of the brain stem regions. Moreover, postnatal follow-up MRI confirmed the prenatal findings and showed additional morphological information such as vascular anatomy [7]. Furthermore, Magnetic Resonance Angiography is the optimal investigation to visualize the relationship of the sac to the venous sinuses. While CT scans are used to detect the extent of cranial defect [8].

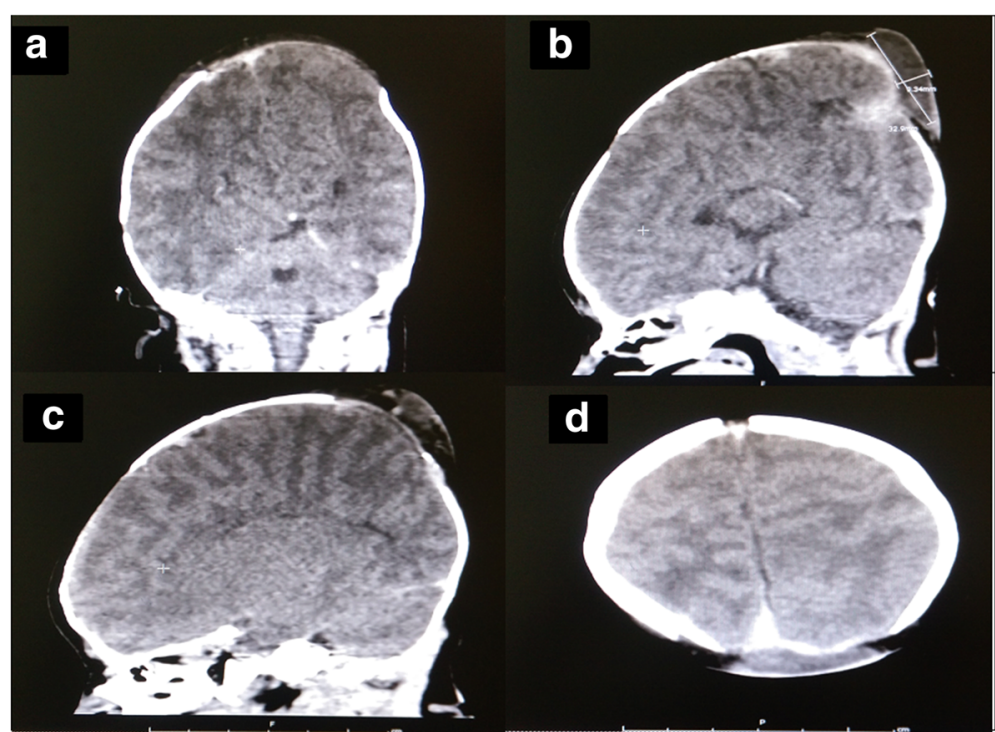

Fig. 1 Non-contrast CT scan with no areas of hypo or hyper attenuation as seen in the coronal section D. An evidence of wide posterior fontanel through which part of the left parietal lobe is herniated with maximum dimensions of $32 \times 10$ mm approximately on sagittal plane in B\&C.No deformity of the ventricular system or evidence of intra or extra axial blood collection was noted through the four parts $A B C \& D$ 


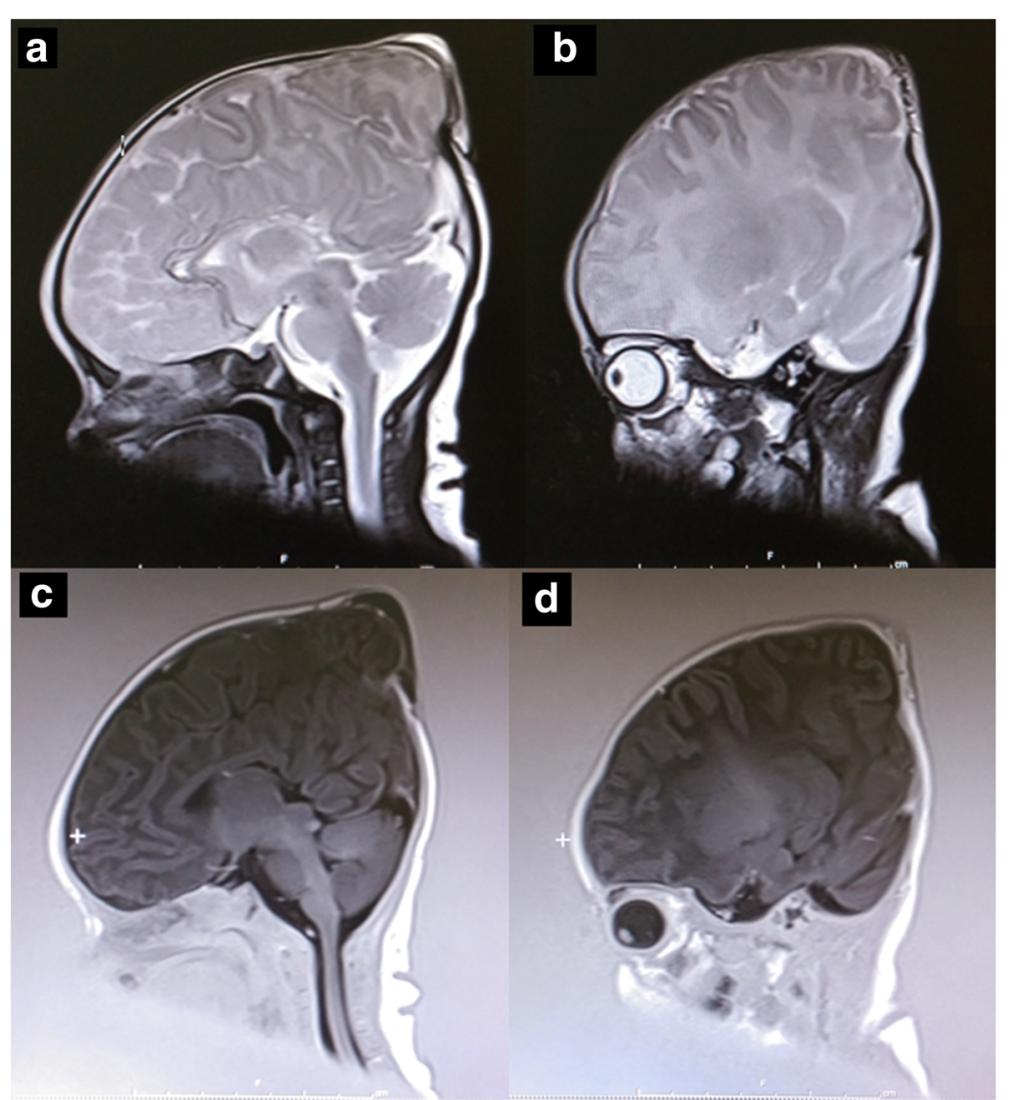

Fig. 2 Axial T1, T2 weight MRI on A\&B showing no evidence of brain parenchymal injury with widening of the posterior fontanel measuring around $3 \times 3 \mathrm{~cm}$. Flair weighted MRI on C\&D that shows a widening of the posterior fontanel with evidence of partial left parietal lobe herniation covered with CSF with no evidence of underlying brain parenchymal abnormal signal or mass with no intra or extra axial areas blood signal

Several surgical techniques are used to preserve normal brain tissue, if present, in the herniated sac. Expansion cranioplasty uses mesh to provide a space for the herniated sac. Another technique is through ventricular volume reduction. It is a two-stage technique; at first, it increases the ventricular pressure and induces hydrocephalus then, through ventriculoperitoneal shunt, the ventricles contract and the herniated tissue repositions intracranially [9]. In addition, for herniated occipital and cerebellar parenchyma, incision is made in the tentorium to create an infratenterial space for the herniated tissue to retract. Currently nasal endoscopy is a valuable procedure in diagnosis and treatment of memnigoencephalocels, it was introduced in early 1980s and emerged as the procedure of choice for meningoencephaloceles [10]. There are some factors that may influence the prognosis of patients with meningoencephalocele, The size of the herniated sac and the amount of brain tissue it contains determine the prognosis of these patients. Frontoethmoidal meningoencephalocele appears to have better prognosis [3]. Zuckerman et al. reported that the reoccurrence of such cases after the initial surgery was approximately $16 \%$ with an average of 7 month interval between the first surgery and the reoccurrence [11].

Meningoencephalocele is categorized according to the location of the herniated sac into occipital and frontoethmoidal subtypes. Antenatally, ultrasonography help evaluating the neural configuration and look for any syndromic characteristics that may influence the fetal outcome.

\section{Abbreviations}

CSF: Cerebrospinal Fluid; CT scan: Computerized Tomography scan; MRI: Magnetic Resonance Imaging; NICU: Neonatal Intensive Care Unit

\section{Funding}

No Funding source.

\section{Availability of data and materials}

The authors declare that all the data supporting the findings of this study are available within the article.

\section{Authors' contributions}

All Authors contributed in writing the papers. $\mathrm{SN}$ : revised the manuscript prior to publication. AA \& AK: Wrote literature review. AN: Wrote the case and obtained consent. All authors approve of the final version of the manuscript. 


\section{Ethics approval and consent to participate}

Consent prior to publication was taken from patient mother.

\section{Consent for publication}

A written consent prior to publication was taken from patient mother.

\section{Competing interests}

The authors declare that they have no competing interests.

\section{Author details}

'College of medicine, University of Sharjah, Sharjah, United Arab Emirates. ${ }^{2}$ Dubai Health Authority, Dubai, United Arab Emirates. ${ }^{3}$ Sharjah Institue of Medical Research, University of Sharjah, Sharjah, United Arab Emirates.

Received: 18 March 2017 Accepted: 27 November 2017

Published online: 14 December 2017

\section{References}

1. Walia B, Bhargava P, Sandhu K. Giant Occipital Encephalocele. Med J Armed Forces India. 2005:61:293-4.

2. Cameron M, Moran P. Prenatal screening and diagnosis of neural tube defects. Prenat Diagn. 2009;29:402-11.

3. Kıymaz N, Yılmaz N, Demir I, Keskin S. Prognostic factors in patients with occipital Encephalocele. Pediatr Neurosurg. 2010;46:6-11.

4. Nejat F, El-Khashab M, Andarabi Y. Progressive skin necrosis of a huge occipital encephalocele. Indian J Plast Surg. 2008:41:82-4.

5. Agthong S, Wiwanitkit V. Encephalomeningocele cases over 10 years in Thailand: a case series. BMC Neurol. 2002;2:3.

6. Wright C, Healicon R, English C, Burn J. Meckel syndrome: what are the minimum diagnostic criteria? J Med Genet. 1994;31:482-5.

7. Kasprian G, Paldino M, Mehollin-Ray A, Shetty A, Williams J, Lee W, Cassady C. Prenatal imaging of occipital Encephaloceles. Fetal Diagn Ther. 2014;37:241-8.

8. Bir F. MRI and CT imaging of an Intrasphenoidal Encephalocele: a case report. Pol J Radiol. 2014;79:360-2.

9. Gallo AE Jr. Repair of giant occipital encephaloceles with microcephaly secondary to massive brain herniation. Childs Nerv Syst. 1992;8:229-30.

10. Bozinov O, Tirakotai W, Sure U, Bertalanffy $\mathrm{H}$. Surgical closure and reconstruction of a large occipital encephalocele without parenchymal excision. Childs Nerv Syst. 2005;21:144-7.

11. Zuckerman J, Stankiewicz J, Chow J. Long-term outcomes of endoscopic repair of cerebrospinal fluid leaks and Meningoencephaloceles. Am J Rhinol. 2005:19:582-7.

\section{Submit your next manuscript to BioMed Central} and we will help you at every step:

- We accept pre-submission inquiries

- Our selector tool helps you to find the most relevant journal

- We provide round the clock customer support

- Convenient online submission

- Thorough peer review

- Inclusion in PubMed and all major indexing services

- Maximum visibility for your research

Submit your manuscript at www.biomedcentral.com/submit
Biomed Central 